\title{
An approach for experiment evaluations for multiple harvests crops based on non-linear regression
}

\author{
Alessandro Dal'Col Lúcio ${ }^{* 1} \mathbb{D}$; Maria Inês Diel ${ }^{1} \mathbb{D}$; Bruno G Sari ${ }^{1 \mathbb{D}}$ \\ ${ }^{1}$ Universidade Federal de Santa Maria (UFSM), Santa Maria-RS, Brasil; adlucio@ufsm.br (*author for correspondence); mariaines.diel@ \\ hotmail.com; brunosari@hotmail.com
}

\begin{abstract}
Biologically based growth models can be an alternative in identifying the productive response of multiple harvest vegetables. By interpreting the estimates of the parameters of the models, it is possible to estimate the total production, the rate of fruit production, and the moment when the crop reaches its maximum production potential. Besides, by estimating confidence intervals, these responses can be compared between genotypes or between different treatments. Therefore, the purpose of this manuscript is to present a literature review, and a detailed step-by-step, to interpreting the evolution of the production cycle of vegetables with multiple harvests crops based on non-linear regression. All the requirements that must be met in this type of analysis were presented in detail based on non-linear regression, providing the necessary steps for this type of analysis in details. Demonstration is given using data from strawberry cultivation along with the associated R scripts and interpretation of analysis output in material supplemental. This approach can allow for more relevant inferences than standard means analyses through better examination and modeling of the underlying biological processes.
\end{abstract}

Keywords: horticulture, logistic model, regression models, nonlinear model, precocity, production.

\section{RESUMO}

Uma abordagem para avaliações de experimentos para culturas de múltiplas colheitas baseado em regressão não linear

Modelos de crescimento de base biológica podem ser uma alternativa na identificação da resposta produtiva de hortaliças de múltiplas colheitas. Ao interpretar as estimativas dos parâmetros dos modelos, é possível estimar a produção total, a taxa de produção de frutos e o momento em que a cultura atinge seu potencial máximo de produção. Além disso, estimando intervalos de confiança, essas respostas podem ser comparadas entre genótipos ou entre diferentes tratamentos. Portanto, o objetivo do manuscrito foi apresentar uma revisão de literatura em um passo a passo para análise e interpretação do ciclo de produção de hortaliças de múltiplas colheitas, com base em regressão não linear. Todos os requisitos que devem ser atendidos neste tipo de análise foram apresentados detalhadamente, fornecendo o passo a passo necessário para análises de regressão não linear. A demonstração é realizada usando dados do cultivo de morango junto com os scripts $\mathrm{R}$ associados e a interpretação da saída da análise em um material suplementar. Esta abordagem pode permitir inferências mais relevantes do que análises tradicionais realizadas, através de um melhor exame e modelagem dos processos biológicos subjacentes.

Palavras-chave: horticultura, modelo logístico, modelos de regressão, modelo não linear, precocidade, produção.

\section{Received on January 14, 2021; accepted on July 19, 2021}

$\mathrm{T}$ he vegetable production chain has high economic and social importance worldwide, contributing to thousands of direct and indirect jobs in the sector, in addition to being in the main meals worldwide. In the past two decades, world vegetable production has increased approximately $60 \%$ compared to 1990 (Parajuli et al., 2019) The increase in demand is basically due to the benefits that the consumption of vegetables brings to human health, mainly because they are a potential source of phenolic acids, vitamins, and minerals (Rashmi \& Negi, 2020) being suggested by nutritionists and doctors.

Due to the increase in vegetable consumption worldwide, research needs to be constantly updated to improve agricultural and production practices and quality. Thus, producers start to produce more and with greater sustainability, while placing quality vegetables on the market for consumers. These studies and researches require that the results obtained be of high experimental precision (Lúcio \& Sari, 2017).

In research with vegetables, variability between plants is a problem, especially in crops with characteristics of multiple harvests, such as strawberries, cucumbers, tomatoes, etc. (Cargnelutti Filho et al., 2004; Lúcio \& Sari, 2017). This situation occurs due to the uneven maturation of the fruits due to physiological characteristics and the growth habit. This means that the researcher needs to harvest the staggered production and, in some of these harvests, the plant may not have fruit or present fruit not suitable for harvest (Cargnelutti Filho et al., 2004; Lúcio \& Benz, 2017). The immediate consequence of this situation is the 
presence of zero values causing the database to be over dispersed (Carpes et al., 2010; Lucio et al., 2016; Sari et al., 2019b).

Several vegetables are harvested during the production cycle. Multiple harvests can be considered as repeated measures over time, as the same plants have their production measured with each new harvest (Lúcio et al., 2015). Strategy to minimize the effects that this situation causes, by accumulating the variables measured in each plant, allowing the application of nonlinear regression analysis techniques to the estimated values for each variable was by Lúcio et al. (2015) presented.

Among nonlinear regressions, bio-based growth models can be an alternative in identifying the productive response of multi-crop vegetables (Mischan et al., 2011; Paine et al., 2012; Sari et al., 2018). By interpreting the estimates of the parameters of the models, it is possible to estimate the total production, the rate of fruit production, and the moment when the crop reaches its maximum production potential. Also, using confidence interval estimates, it is possible to compare these estimates between genotypes or between different experimental treatments (Lucio et al., 2016; Sari et al., 2018; Diel et al., 2020a).

The use of nonlinear models for the evaluation of vegetables from multiple harvests presents advantages over the evaluation of experiments using ANOVA and complementary tests of means or linear regressions (Sari et al., 2019b; Diel et al., 2020a, b). Nonlinear models allow for the interpretation of more robust results that would not be possible with other more trivial statistical tests such as, for example, multiple comparisons test between treatment means.

The definition of precocity and the rate of fruit production are examples of interpretations that are important when it comes to vegetables (Diel et al., 2017; Sari et al., 2018). Their definitions are not yet well understood in the field of horticulture and nonlinear models allow them to be defined based on the partial derivatives of the regression model used (Sari et al., 2018).
Thus, the purpose of this manuscript is to present a literature review, and a detailed step-by-step, and an interpretation of the evolution of the production cycle of vegetables with multiple harvests crops based on a nonlinear regression by the logistic model, facilitating its use.

\section{How to organize the data to model production?}

The data used in the example are from an experiment conducted in a randomized block design, with a strawberry cultivar, and four fertilization treatments (organomineral, chemical, mixed organomineral + chemical and peat substrate with mixed fertilization), $\mathrm{T} 1, \mathrm{~T} 2, \mathrm{~T} 3$ and $\mathrm{T} 4$ respectively, in four repetitions and the experimental unit consisting of eight plants. After the fruits were red in color, they were harvested every seven days, totaling seven harvests. The variable evaluated in this example is the mass of fruits per plant $\left(\mathrm{g}_{\text {plant }}{ }^{-1}\right)$.

In the following example, the adjustment of the model will be for the fruit mass variable $(\mathrm{g})$ as a function of the DAT. The fruit mass must be accumulated in each harvest (from the first to the last) $\mathrm{H} 1, \mathrm{H} 1+\mathrm{H} 2, \mathrm{H} 1+\mathrm{H} 2+\mathrm{H} 3$, $\mathrm{H} 1+\ldots \ldots+\mathrm{H} 7$, in four repetitions, for each of the experimental treatments (supplemental material: available at www.horticulturabrasileira.com. br). The adjustment of the non-linear regression model can be performed by means of the repetitions of treatments or for each of the repetitions, in case of individual assessment of each plant that makes up the plot. The decision as to whether the adjustment will be made for the average of repetitions or each repetition rests with the researcher.

\section{Nonlinear regression models}

Nonlinear models are applied in various areas of knowledge to describe the relationship between different variables, these depend on the research area, the specific problem and the type of growth that will be modeled . Many biological scientific processes can be represented by nonlinear functions, such as the growth of animals and plants, which are faster in the initial phase and decrease the speed of growth tending to stability over time (Paine et al., 2012; Mischan \& Pinho, 2014).

Nonlinear regression models, when they present parameters that can be interpreted biologically, can be more suitable than the use of linear models, as can they facilitate the understanding related to growth, mainly if they are based on parameters that allow biological interpretation, and plant growth has a nonlinear behavior (Mischan et al., 2011; Paine et al., 2012).

The assessment of the quality of fit of a nonlinear model for growth data must take into consideration out by the measures of intrinsic and parametric non-linearity (Bates \& Watts, 1988; Sari et al., 2018, 2019b) along with statistics Akaike Information Criteria (AIC), Bayesian Information Criterion (BIC) and the coefficient of determination $\left(\mathrm{R}^{2}\right)$. Non-linearity should be minimized in the most appropriate model (Beale, 1960), the non-use of this measure and the selection of models only for the AIC or BIC is worrying, since interpretations and recommendations may be being made based on highly biased parameters (Sari et al., 2018). Sari et al. (2019b) show that AIC, BIC and $\mathrm{R}^{2}$ do not assess parameter bias and can select models that do not describe biological growth correctly.

Bates \& Watts (1988) defined two measures of nonlinearity: intrinsic nonlinearity $\left(c^{l}\right)$ and parametric nonlinearity $\left(c^{\theta}\right)$. The $c^{l}$ is independent of the parameterization chosen for the adjusted model and does not change its value, $c^{\theta}$ is dependent on the parameterization of the chosen model and can change the value from one parameterization to another. $c^{l}$ values are desired around 0.3 while for $c^{\theta}$ the values must be less than 1 , and when above it means that the model has high non-linearity (Bates \& Watts, 1988; Mazucheli \& Achcar, 2002; Seber \& Wild, 2003; Fernandes et al., 2015). The closer to the linear the model, the convergence in the estimation of the parameters is fast and reliable (Ratkowsky, 1983) .

Parameterizations of the logistic and Gompertz models and two parameterizations of the von Bertalanffy model were tested for strawberry 
production, in order to select the best parameterization that would estimate non-biased parameters (Box 1). Each parameterization within each model presented different results of parametric nonlinearity, and within the logistic and Gompertz models it had parameterization with low non-linearity and also parameterization with high non-linearity; for both parameterizations of the von Bertalanffy model used, the non-linearity was high, estimating biased parameters and preventing its use to model strawberry production (Diel et al., 2019). In many cases, the use of incorrect parameterization of nonlinear models can cause errors in the selection of the best model and in the interpretation of parameters (Fernandes et al., 2015).

Several authors have been working with nonlinear models in the study of growth curves, in the most diverse areas, studies with Italian zucchini, peppers and cherry tomatoes can be cited (Lúcio et al., 2015, 2016), cucumber (Neto et al., 2013), strawberry (Diel et al., 2019, 2020b), tomato (Sari et al., 2019a, b ), eggplant (Sari et al., 2018), and biquinho pepper (Diel et al., 2020a). Among the nonlinear functions, we can mention the logistic models, by von Bertalanffy and the Gompertz model, which are widely used in agricultural studies.

The logistic growth model is the most suitable for the culture of multiple harvests and Sari et al. (2018) determined and interpreted the critical points of a model and their interpretations. Diel et al. (2019) adjusted several parameterizations of the logistical, von Bertalanffy and Gompertz models and concluded that the logistic model is the most appropriate as it presents unbiased results. Similarly, Sari et al. (2019a, b) determined the logistic model as the best model for characterizing tomato production.

\section{Some nonlinear models}

The logistic model can be used to represent data in which the initial growth is exponential and after the inflection point is asymptotic (Mischan \& Pinho, 2014). Maia et al. (2009) used nonlinear models to describe growth curves in banana trees, and the logistic model showed better fit quality. Prado et al. (2013) concluded that the logistic model was the most adequate to describe the growth, in diameter, longitudinal and transversal, of green dwarf coconut fruits. Lúcio et al. (2015) concluded that the logistic model was the most adequate to describe the growth, in diameter, longitudinal and transversal, of green dwarf coconut fruits.

Von Bertalanffy's model was derived from a study model called allometric relationships of organisms, but it has also been used in studies of growth in the plant environment (Mischan \& Pinho, 2014). Lúcio et al. (2016) used nonlinear models to estimate the production of green beans and concluded that in relation to the quality of the adjustments made, the logistic and von Bertalanffy models presented very similar estimates of quality indicators; the same authors observed that the von Bertalanffy model always showed higher values of $\beta_{1}$ (asymptote) and lower values of $\beta_{3}$ (production rate) when compared to the logistic model. When using AIC and BIC as measures of fit quality for data from multiple harvests, one can mistakenly select the von Bertalanffy model as appropriate. However, as seen in Diel et al. (2019), this model had the lowest AIC values, high nonlinearity values and overestimated parameter estimates, indicating its poor performance in describing strawberry production data. Likewise, this model is not suitable for modeling growth of multi-crop vegetables (Sari et al., 2018, 2019a, b).

The Gompertz model has initial exponential growth and then asymptotic (Mischan \& Pinho, 2014). This model is useful in biological studies, it does not have a minimum or a maximum, but it has an inflection point, growing until it reaches the maximum growth rate at its inflection point, then there is a decrease in growth until it reaches an asymptotic value. The Gompertz model is more similar to the logistic model and, depending on the parameterization used, it presents a good quality of fit determined by the non-linearity measures. Diel et al. (2019) tested three parameterizations of the Gompertz model with low intrinsic and parametric nonlinearity. However,

Box 1. Parameterization of logistic, Gompertz and von Bertalanffy models used to adjust mass and number of fruits in strawberry. Santa Maria, UFSM, 2020.

\begin{tabular}{|l|c|c|c|}
\hline \multicolumn{1}{|c|}{ Par $^{*}$} & Logistic & Gompertz & von Bertalanffy \\
\hline Par 1 & $y i=\frac{\beta_{1}}{1+e^{\left(\beta_{2}-\beta_{3} x_{i}\right)}+\varepsilon_{i}{ }^{1}}$ & $Y_{i}=\beta_{1} * e^{-e^{\left(\beta_{3}{ }^{*}\left(\beta_{2}-x_{i}\right)\right)}}+\varepsilon_{i}$ & $Y_{i}=\beta_{1}\left(1-\beta_{2} e^{\left(\beta_{3} x_{i}\right)}\right)^{3}+\varepsilon_{i}$ \\
\hline $\operatorname{Par} 2$ & $Y i=\frac{\beta_{1}}{1+\mathrm{e}^{\beta_{2}{ }^{*}\left(\beta_{3}-x i\right)}+\varepsilon_{i}}$ & $Y_{i}=\beta_{1} * e^{-e^{\left(\beta_{2}-\beta_{3}{ }^{*} x_{i}\right)}}+\varepsilon_{i}$ & $Y_{i}=\beta_{1} *\left(1-e^{-\beta_{2}-\beta_{3}{ }^{*} x_{i}}\right)^{3}+\varepsilon_{i}$ \\
\hline $\operatorname{Par} 3$ & $Y_{i}=\frac{\beta_{1}}{1+\beta_{2}{ }^{*} e^{-\beta_{3}{ }^{*} x_{i}}}+\varepsilon_{i}$ & $Y_{i}=\beta_{1} * e^{\left[-\beta_{2} e^{\left(\beta_{3} 3 x i\right)}\right]}+\varepsilon_{i}$ & \\
\hline
\end{tabular}

*Par $=$ parameterizations; ${ }^{1} Y_{i}=$ the dependent trait (accumulated number or weight of fruits per plant); $X_{i}=$ accumulated thermal sum (STa), in degree days, elapsed time of transplant of seedlings to harvest (independent trait); $\beta_{1}$ represents the horizontal asymptote, that is, the point of stabilization of plant growth; $\beta_{2}$ is the parameter that indicates the distance (in relation to abscissa) between the initial value and the asymptotes; $\beta 3$ is a parameter associated with the growth rate and represents random error. 
this model overestimates the parameters in relation to the original values. Sari et al. (2019a) did not select the Gompertz model because statistically this model presented biased parameters that could lead to a misinterpretation about the productive behavior of the tested culture.

\section{The logistic model for fruit mass}

The model used for the example (supplemental material) will be the logistics

$$
y=\frac{\beta_{1}}{1+\exp \left(\beta_{2}-\beta_{3} x\right)}+e
$$

where $Y_{i}$ is the mean mass of fruits per plant (dependent variable); $X_{i}$ is the accumulated thermal sum $\left(\mathrm{TS}_{\mathrm{a}}\right)$, in degree days, from the seedling transplant up to the $i^{\text {th }}$ harvest (independent variable); $\beta_{1}$ is the asymptotic value, and its values represent the total production of treatments; $\beta_{2}$ is a parameter that reflects the distance between the initial value (observation) and the asymptote; and $\beta_{3}$ is the parameter associated with the growth rate. This model is already indicated in several studies as being the most suitable for multiple harvests crops, as in the strawberry (Diel et al., 2019, 2020b), tomato (Sari et al., 2019b) eggplant (Sari et al., 2018), and biquinho pepper (Diel et al., 2020a ).

The parameter estimates were obtained by using Ordinary Least Squares Method, using a Gauss-Newton algorithm (Bard, 1974). This procedure was performed using a ' $n l s$ ' function in a R software. With the model chosen and fit, its models assumptions must be tested: normality, homogeneity, and independence of residues. ShapiroWilk tests were used to test normality (Shapiro \& Wilk, 1965), Breusch-Pagan
(1979) for homogeneity, and DurbinWatson (1950) for the independence of errors. Compliance with the assumptions is fundamental to estimate precise confidence intervals for the parameters. According to the tests performed, most of the model's assumptions were met. For T2 only, the assumption of independence of errors was not met (Table 1). Thus, the estimates of the model parameters can be biased. When the model's assumptions are not fully met, confidence intervals for the parameters can be estimated through bootstrap resampling, which is an efficient technique to work around these problems (Ratkowski, 1983; Souza et al., 2010; Diel et al., 2019).

Another important measure when adjusting the nonlinear regression model is the determination of intrinsic and parametric nonlinearity measures. The intrinsic non-linearity does not depend on the parameterization of the model used, while the parametric is linked with the parameterization of the chosen model (Bates \& Watts, 1988, 2007).

When the parametric nonlinearity is high, that is, greater than 1 , it means that the adjusted parameterization used is not adequate, and can reproduce estimates that lead to errors in the interpretation of the results (Bates \& Watts, 1988, 2007; Seber \& Wild, 2003; Zeviani et al., 2012). When this happens, the researcher must adjust another parameterization of the model. This can be seen in more detail at Diel et al. (2019) and Fernandes et al. (2015).

Non-linearity measures are very important to verify that the models have parameters close to being impartial. To evaluate these measures in the $\mathrm{R}$ software, use the function 'rms.curv' in package MASS. This function returns

Table 1. p-values for the tests of normality, heteroscedasticity and error independence, estimates of non-linearity of the logistic model adjusted for fruit mass $\left(\mathrm{g} \mathrm{plant}^{-1}\right)$ strawberry. $\mathrm{SW}=$ Shapiro-Wilk; $\mathrm{BP}=$ Breusch-Pagan; $\mathrm{DW}=$ Durbin Watson; $\mathrm{C}^{\mathrm{I}}=$ intrinsic nonlinearity; $\mathrm{C}^{\theta}=$ parametric nonlinearity. Santa Maria, UFSM, 2020.

\begin{tabular}{lccccc}
\hline Treatment & SW & BP & DW & $\mathbf{C}^{\mathbf{I}}$ & $\mathbf{C}^{\boldsymbol{\theta}}$ \\
\hline T1 & 0.46 & 0.41 & 0.43 & 0.11 & 0.42 \\
T2 & 0.45 & 0.07 & 0.02 & 0.05 & 0.17 \\
T3 & 0.32 & 0.11 & 0.96 & 0.19 & 0.62 \\
T4 & 0.41 & 0.41 & 0.18 & 0.19 & 1.13 \\
\hline
\end{tabular}

the parametric and intrinsic nonlinearity measures proposed by Bates \& Watts (1988). The lower values of these measures indicate that the parameters are close to being impartial.

In the example shown(supplementary material) it is noticed that the results of the intrinsic and parametric nonlinearity measures agree, for the $\mathrm{T} 1, \mathrm{~T} 2$, and T3 treatments, presenting a good fit, because they have values less than 0.3 and 1 , respectively (Table 1 ). This result indicates that the model and parameterization that are being adjusted can be used to interpret the mass of strawberry fruits according to the days after transplantation (DAT). However, for $\mathrm{T} 4$ the parametric nonlinearity was above 1 , indicating that this parameterization may cause biased parameters in this treatment, and, in this case, another parameterization should be adjusted (Table 1).

\section{Critical points of the model}

In addition to the adjusted $\beta$ parameters, it is also possible to adjust the critical points of the function (Table 2 ). These are estimated by equalizing the partial derivatives of the function to zero, according to the methodology described in Mischan et al. (2011) and Mischan \& Pinho (2014): maximum acceleration point (MAP), inflection point (IP), maximum deceleration point (MDP) and asymptotic deceleration point (ADP). The concentration of production is defined by the difference between MDP and MAP. The CI of each critical point and the concentration of production are obtained by the difference between the quantiles $95^{\text {th }}$ and $2,5^{\text {th }}$, via bootstrap (Table 2).

The critical points of the function used to characterize the productive behavior of the crop are obtained using the derivatives in relation to time (in days or degrees Celsius day ${ }^{-1}$ ) as follows:

1-Inflection point $($ IP $)=$ which represents the moment when the maximum fruit production rate occurs, and the time at which this point is reached means the precocity of production (Sari et al., 2018). It is calculated as $\frac{d^{2} y(x)}{d x^{2}}=0$ (Mischan et al., 2011). 
2-Maximum acceleration point (MAP) and maximum deceleration point $(\mathrm{MDP})=$ The MAP indicates the slowness of the initial production and the degree of maturation of the plants at the beginning of the harvest. The later the MAP occurs, the smaller the increase in production in the first harvests, indicating a lower degree of fruit maturation. The MDP means the decrease in the rate of fruit production. In addition, the interval between MAP and MDP indicates the concentration of production (Sari et et al., 2018). It is calculated as $\frac{d^{3} y(x)}{d x^{3}}=0$ (Mischan et al., 2011).

3-Asymptotic deceleration point (ADP): indicates the time of harvest when the increases in production become insignificant (Sari et al., 2018, 2019b). For the calculation $\frac{d^{4} y(x)}{d x^{4}}=0$ (Mischan et al., 2011).

\section{Estimation of confidence intervals by resampling}

In addition to being useful in comparing treatment, estimating confidence intervals (CI) for the model parameters and their adjusted critical points, CIs can be useful when problems in relation to meeting the assumptions in nonlinear models (heterogeneity, normality and independence of the errors), the estimation bootstrap technique is an alternative to the inferential process and also a diagnostic tool (Efron \& Tibshirani, 1986; Souza, 1998, Souza et al., 2010). The use of bootstrap for nonlinear models is the best way to analyze the distributional properties (Ratkowski, 1983). The use of IC by resampling increases the reliability of the results in addition to allowing comparisons between treatments to be made, as can be seen in Diel et al. (2020a).

The confidence intervals (CI) of the parameters are estimated using the function ' $n l s B o o t$ '. The CI is obtained by the difference between the quantiles $95^{\text {th }}$ and $2.5^{\text {th }}$, using the values of the previously adjusted model (see supplemental material available at www. horticulturabrasileira.com.br). To plot the results on the graph, use the function 'ggplot' .The output of this program (supplementary material) is presented with the graph below where it is possible to make comparisons between the estimates obtained for each of the experimental treatments evaluated.

Interpreting the confidence intervals of the model parameters and their critical points

The interpretation of the confidence intervals is performed for each treatment, making comparisons between them. If one treatment does not differ significantly from another, the confidence intervals overlap. If the treatment intervals do not overlap, treatments can be statistically and significantly different.

For example, in the first interval graph, the T1 and T3 intervals overlap but do not overlap with $\mathrm{T} 2$ and $\mathrm{T} 4$ (Figure 1). Therefore, T2 and T4 are significantly different from other treatments. Likewise, the T2 and T4 intervals do not overlap, indicating that these treatments are significantly different from each other.

The estimate of parameter $\beta_{1}$ is interpreted as being the asymptote. In biological terms, it means the production that a given treatment reached during the crop production cycle (Mischan et al., 2011). Thus, the most productive treatment, in this example, was $\mathrm{T} 2$, reaching about 280 grams per plant and was significantly superior to the other treatments, followed by T4 (Figure 1, Table 2). The treatments $\mathrm{T} 3$ and $\mathrm{T} 1$ did not differ from each other (this interpretation is because the interval of one does not overlap the average of the other).

The parameter estimate $\beta_{2}$ previously was defined as without biological interpretation because this is the parameter that reflects the average of the distance between the initial value and the asymptote. However, Diel et al. (2019) and Sari et al. (2018) presented the $\beta_{2}$ as a measure of productive precocity, that is, how soon a given treatment produced in relation to the others. Treatments with lower values of the parameter $\beta_{2}$, indicate fruit maturation at the beginning of the harvest, that is, greater fruiting at the beginning of the production cycle. In the example shown here, all treatments showed significant differences from each other, with treatment $\mathrm{T} 4$ being the earliest, while $\mathrm{T} 2$ being the most delayed treatment (Figure 1). Note that even the T4 treatment, being the earliest, is not the most productive, and with this analysis increases the robustness, the basis of interpretation, and the technical recommendation to the producer. This way, he will be able to better plan his cultivation based on the results he intends with the volume of production, and with the advance offer of his product to the consumer market.

The parameter interpretation $\beta_{3}$ in biological terms, represents the rate of fruit production (Mischan et al., 2011; Sari et al., 2018). Thus, the treatment with the lowest estimate of $\beta_{3}$ will have

Table 2. Parameters of the estimated logistic model for mass of strawberry ( $\beta_{1}$ represents the production, $\beta_{2}$ represents the precocity of production and $\beta_{3}$ represents the rate of fruit production) and its critical points (IP = inflection point; MAP= maximum acceleration point; $\mathrm{MDP}=$ maximum deceleration point; $\mathrm{ADP}=$ asymptotic deceleration point; concentration= MDP-MAP). Santa Maria, UFSM, 2020.

\begin{tabular}{lcccccccc}
\hline Treatment & $\boldsymbol{\beta}_{\mathbf{1}}$ & $\boldsymbol{\beta}_{\mathbf{2}}$ & $\boldsymbol{\beta}_{\mathbf{3}}$ & MAP & MDP & ADP & IP & $\begin{array}{c}\text { Concen- } \\
\text { tration }\end{array}$ \\
\hline $\mathrm{T} 1$ & 166.10 & 32.30 & 0.16 & 185.09 & 200.70 & 206.60 & 192.90 & 15.61 \\
$\mathrm{~T} 2$ & 281.90 & 38.50 & 0.19 & 189.00 & 202.30 & 207.30 & 195.70 & 13.30 \\
$\mathrm{~T} 3$ & 165.10 & 35.30 & 0.18 & 186.00 & 200.40 & 205.70 & 193.10 & 14.40 \\
$\mathrm{~T} 4$ & 177.80 & 25.20 & 0.13 & 182.90 & 203.10 & 2010.50 & 193.00 & 20.20 \\
\hline
\end{tabular}


a higher production rate, that is, it will have remained a long time producing. On the contrary, that treatment with the highest estimate of $\beta_{3}$ will have a lower production rate, because production occurred in a shorter period (Sari et al., 2018).

In the example shown here, the T4 treatment showed a higher production rate, that is, despite the lower estimate of the parameter $\beta_{2}$ show the previous production in this treatment, also reached the IP in less time, due to the lower estimate of $\beta_{3}$ in the T4 treatment (Figure 1). The T2 treatment, for example, presented a lower production rate, that is, it remained less time producing, but it presented a delayed production about T4 (compared by $\beta_{2}$ ) and it took longer to reach the IP (maximum production).

The critical point MAP (maximum acceleration point) indicates the moment when the exponential increase in production in treatments starts. The high value of MAP is related to slow increases in production at the beginning of the harvest, that is, the initial harvests produce few fruits and are associated with the degree of maturation of the plants when harvests begin (Sari et al., 2018). In fact, in the example presented, what has already been identified with the estimates of $\beta_{2}$ and $\beta_{3}$, since the T2 treatment presented the highest MAP estimate (Figure 1, Table 2), indicating that production was slower at the beginning of the harvest compared to T4, which was earlier and showed an initial increase in the earlier harvest (evidenced by the lower value of MAP).

The inflection point (IP) represents the time spent by the plants to reach maximum production and can confirm the precocity of a certain experimental treatment. When plants start production at the beginning of the production cycle and have a high production rate, this treatment will probably reach the IP in less time (treatments in full production). The sooner that moment arrives, the earlier the genotype or the productive stimulus provided by the experimental treatment is (Mischan et al., 2011; Sari et al., 2018).

In the example presented here, it is not that the T4 treatment reached the
IP in a shorter period, but did not show significant differences with the T3 and $\mathrm{T} 1$ treatments, while the T2 treatment reached the IP in a long time (Figure 1).
As the T2 treatment started production later (higher estimate of $\beta_{2}$ ), it presented slow increments at the beginning of the harvests (higher estimate of MAP) and,

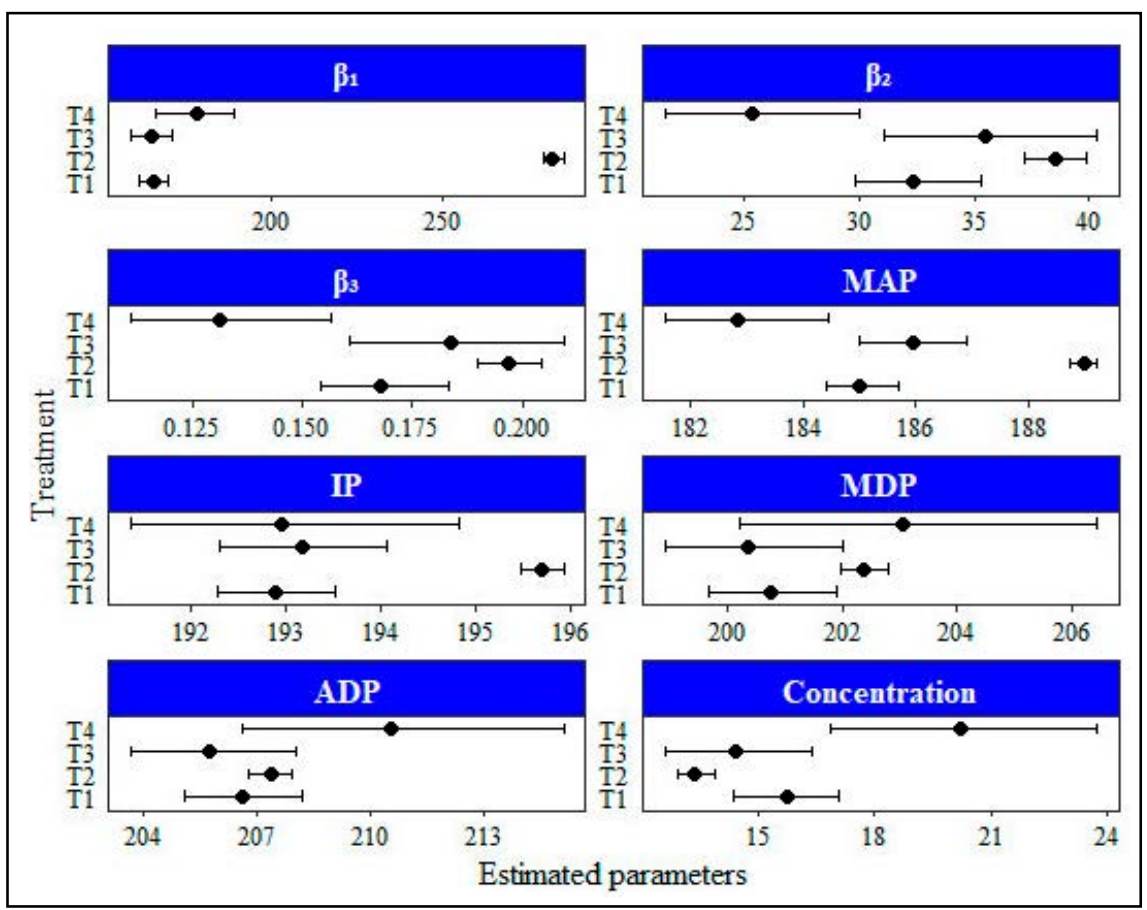

Figure 1. Confidence intervals for the parameters and critical points of the nonlinear logistic model estimated via bootstrap. $\beta_{1}=$ production; $\beta_{2}=$ precocity of production; $\beta_{3}=$ rate of fruit production; $\mathrm{MAP}=$ maximum acceleration point; $\mathrm{IP}=$ inflection point; $\mathrm{MDP}=$ maximum deceleration point; $\mathrm{ADP}=$ asymptotic deceleration point; Concentration= MDP-MAP, for the different treatments. Santa Maria, UFSM, 2020.

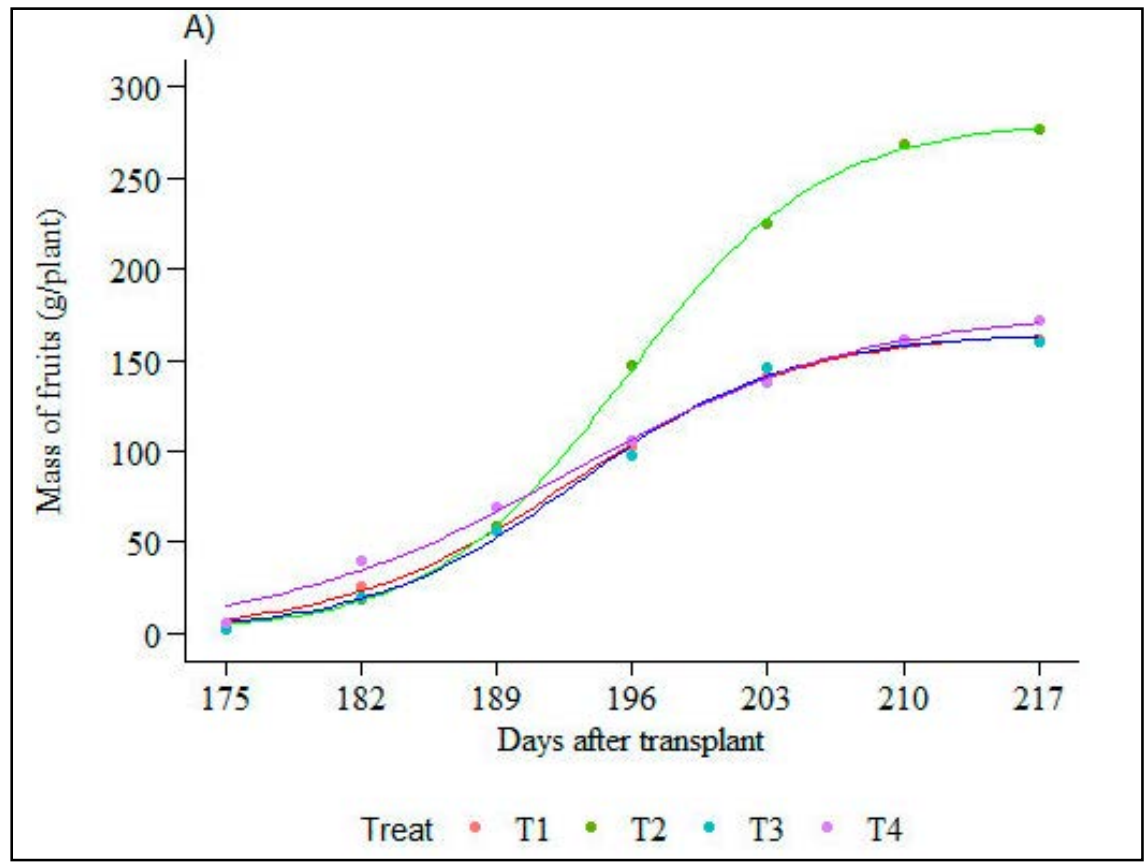

Figure 2. The logistic model adjusted for fruit mass $\left(\mathrm{g} \mathrm{plant}^{-1}\right)$ as a function of the days after transplanting the seedlings (DAT) for four different experimental treatments. Santa Maria, UFSM, 2020. 
thus, it is evident that it would reach its maximum production in a longer time (higher estimate of IP).

The maximum deceleration point (MDP) indicates the end of the period of exponential growth in fruit production. The T3 and T1 treatments started to reduce their production before the T4 and T2 treatments (Figure 1). This condition is reflected in the concentration of production, which is determined by the difference between MDP and MAP (Sari et al., 2018), the T4 treatment is the one that remained the longest in production, even though it was less productive than the T2 (higher estimate of $\beta_{1}$ ).

The asymptotic deceleration point (ADP) shows how long the treatment has shown significant growth during harvests (Mischan et al., 2011; Sari et al., 2018). Significant differences were observed between some treatments. The T3 and T1 treatments are characterized by producing fruits for a shorter time and the increments in production are no longer significant (Figure 1), followed by the T2 treatment, while the T4 decreases the increments in production over a longer period (evidenced by the greater estimate of ADP).

\section{Model Critical Points Chart}

A graph plotting the adjusted model (A), the inflection point (IP) (B), and all critical points, IP, MAP, MDP, and ADP (C) can be performed (see supplementary material), so that the performance of the evaluated treatments can be visualized graphically (Sari et al., 2019b; Diel et al., 2020 b)

The graphs show the productive response of each treatment. In this display example, the greatest production was shown by the $\mathrm{T} 2$ treatment (Figure 2 ). It is also possible to identify the highest production at the beginning of the T4 treatment harvests, as discussed earlier.

By evaluating the graphs shown in Figure 3, it is possible to visualize the treatments that reached the IP in a shorter period. The earlier in the productive cycle this moment arrives, the earlier the genotype or the productive stimulus provided by the experimental treatment is. In the example presented

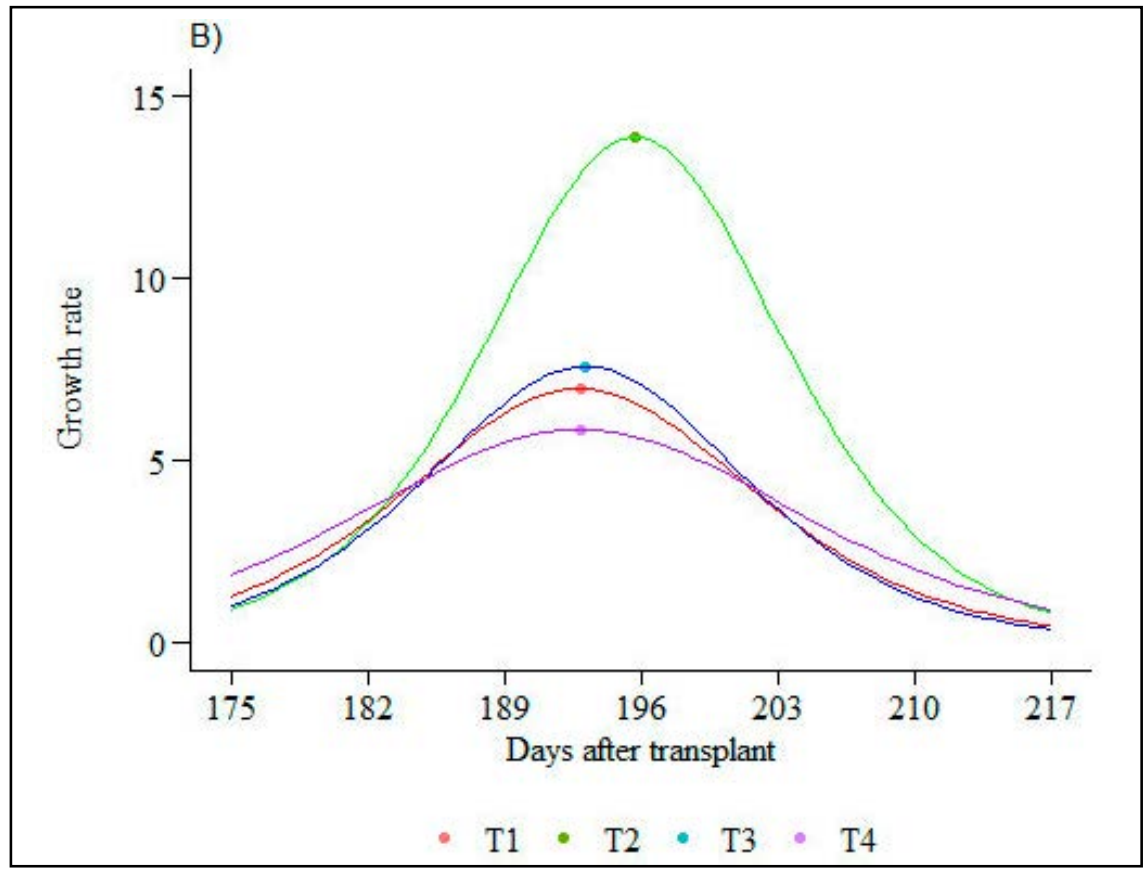

Figure 3. Inflection points estimated in the adjusted models in each experimental treatment. Santa Maria, UFSM, 2020.

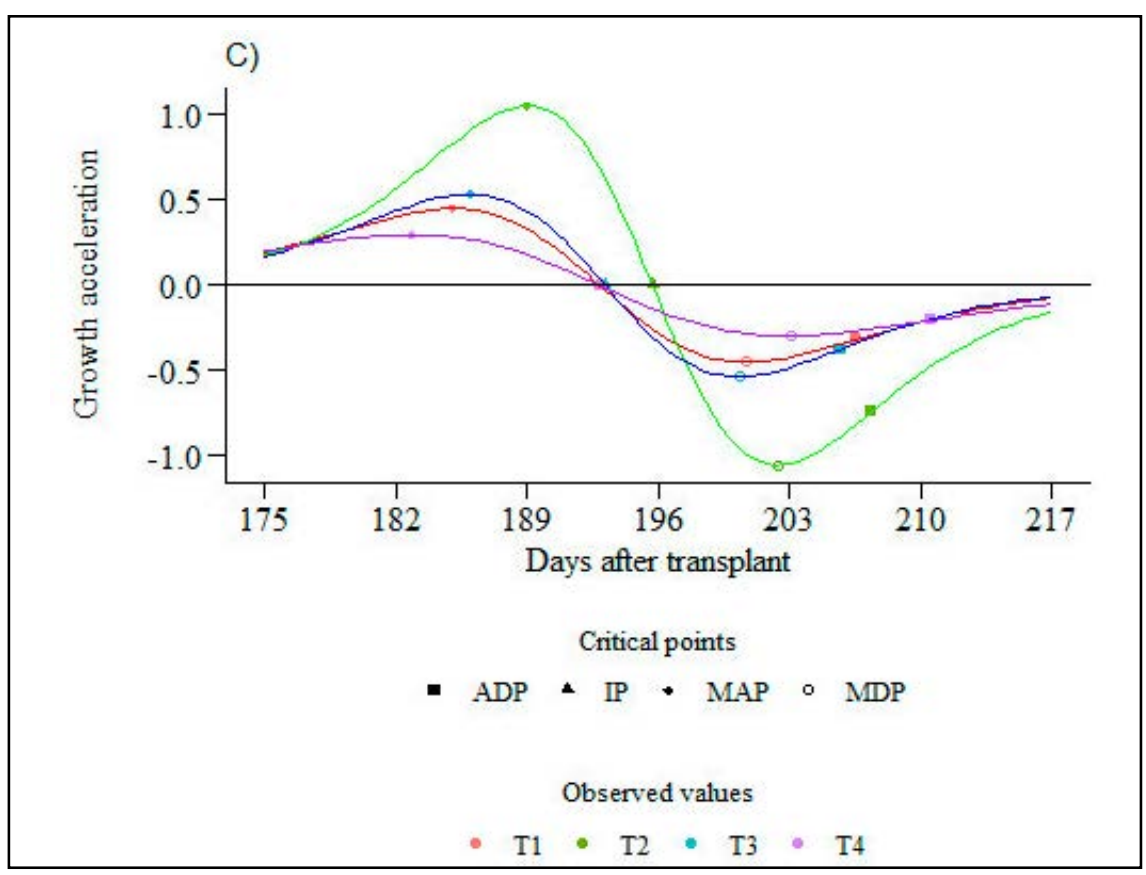

Figure 4. Points of asymptotic deceleration (ADP), inflection (IP), maximum acceleration (MAP), and maximum deceleration (MDP), estimated in the models adjusted for each experimental assessment. Santa Maria, UFSM, 2020.

here, it is not that the T4 treatment reached the IP earlier (Figure 3), but has no significant differences with the $\mathrm{T} 3$ and $\mathrm{T} 1$ treatments, while the T2 treatment reached the IP later. As noted earlier, treatment $\mathrm{T} 2$ started production later (higher estimate of $\beta_{2}$ ), it presented slow increases at the beginning of the harvests (higher estimate of MAP) and thus reached the maximum of production later (higher estimate of IP). All the critical points are plotted and it is possible to visualize the productive response 
of each experimental treatment. The ones that have the biggest differences between them are T4 and T2 (Figure 4).

\section{Final considerations}

The application of the nonlinear regression analysis methodology with the adjustment of a logistic model was presented, allowing the researcher to explore, identify and interpret, in a more robust, complete, and adequate way, the entire evolution of the productive cycle of crops of multiple harvests.

With the application of this method of analysis, it is possible to proceed with comparisons of the estimates of the parameters and the critical points of the adjusted regression model, showing the differences presented by the experimental treatments. In this way, the breadth of the technical recommendation from the results obtained is increased.

\section{REFERENCES}

BARD, Y. 1974. Nonlinear parameter estimation. 1.ed, Minnesota: Academic Press, v.1 341p.

BATES, DM; WATTS, DG. 1988. Nonlinear regression analysis and its applications. $2^{\circ}$ ed. New York: John Wiley and Sons Inc. v.85 i-xivp.DOI: 10.1002/9780470316757.

BATES, DM; WATTS, DG. 2007. Nonlinear regression analysis and its applications. New York: John Wiley and Sons Inc., 392p.

BEALE, EML.1960. Confidence regions in non-linear estimation. Journal of the Royal Statistical Society 22:41-88.

BREUSCH, TS; PAGAN, AR. 1979. A simple test for heteroscedasticity and random coefficient variation. Econometrica 47: 1287-1294.

CARGNELUTTI FILHO, A; RADIN, B; MATZENAUER, R; STORCK, L. 2004. Número de colheitas e comparação de genótipos de tomateiro cultivados em estufa de plástico. Pesquisa Agropecuária Brasileira 39: 953-959.

CARPES, RH; LÚCIO, AD; LOPES, SJ; BENZ, V; HAESBAERT, F; SANTOS, D. 2010. Variabilidade produtiva e agrupamentos de colheitas de abobrinha italiana cultivada em ambiente protegido. Ciência Rural 40: 264-271

DIEL, MI; GIACOMINI, B; TIAGO, S; MARCOS, O; MARQUES, V. 2020a. Production of biquinho pepper in different growing seasons characterized by the logistic model and its critical points. Ciência Rural 50: e20190477.
DIEL, MI; LÚCIO, AD; SARI, BG; OLIVOTO, T; PINHEIRO, MVM; KRYSCZUM, DK MELO, PJ; SCHMIDT, D. 2020b. Behavior of strawberry production with growth models: a multivariate approach. Acta Scientiarum Agronomy 43: e47812.

DIEL, MI; PINHEIRO, MVM; COCCO, C; FONTANA, DC; CARON, BO; PAULA, GM; PRETTO, MM; THIESEN, LA; SCHMIDT, D. 2017. Phyllochron and phenology of strawberry cultivars from different origins cultivated in organic substracts. Scientia Horticulturae 220: 226-232

DIEL, MI; SARI, BG; KRYSCZUN, DK; OLIVOTO, T; PINHEIRO, MVM; MEIRA, D; SCHMIDT, D; LÚCIO, AD. 2019. Nonlinear regression for description of strawberry (Fragaria $x$ ananassa) production. Journal of Horticultural Science and Biotechnology 94: 259-273.

DRAPER, N; SMITH, H. 1981. Applied regression analysis. $2^{\text {th }}$ ed. New York: John Wiley \& Sons Inc. 709p.

DURBIN, BYJ; WATSON, GS. 1950. Biometrika trust testing for serial correlation in least squares regression : I. Biometrika 37: 409-428.

EFRON, B; TIBSHIRANI, R. 1986. Bootstrap methods for standard errors, confidence intervals, and other measures of statistical accuracy. Statistical Science 1: 54-75.

FERNANDES, TJ; MUNIZ, JA; PEREIRA, AA; MUNIZ, FR; MUIANGA, CA. 2015. Parameterization effects in nonlinear models to describe growth curves. Acta Scientiarum. Technology 37: 397

LÚCIO, AD; BENZ, V. 2017. Accuracy in the estimates of zucchini production related to the plot size and number of harvests. Ciência Rural 47: e20160078.

LÚCIO, AD; NUNES, LF; REGO, F. 2015. Nonlinear models to describe production of fruit in Cucurbita pepo and Capiscum annuum. Scientia Horticulturae 193: 286-293.

LUCIO, AD; NUNES, LF; REGO, F. 2016. Nonlinear regression and plot size to estimate green beans production. Horticultura Brasileira 34: 507-513.

LÚCIO, AD; SARI, BG. 2017. Planning and implementing experiments and analyzing experimental data in vegetable crops: problems and solutions. Horticultura Brasileira 35: 316-327.

MAIA, E; SIQUEIRA, DL; SALOMÃO, LCC; PETERNELLI, LA; VENTRELLA, MC; CAVATTE, RPQ. 2009. Development of the banana plants 'Prata Anã' and 'FHIA-01' under the effect of paclobutrazol applied on the soil. Anais da Academia Brasileira de Ciências 81: 275-263.

MAZUCHELI, J; ACHCAR, JA. 2002. Algumas considerações em regressão não linear. Acta Scientiarum. Technology 24: 1761-1770.

MISCHAN, MM; PINHO, SZ. 2014. Modelos não lineares: Funções assintóticas de crescimento. 1.ed. São Paulo: Cultura Acadêmica. 184p.
MISCHAN, MM; PINHO, SZ; CARVALHO, LR. 2011. Determination of a point sufficiently close to the asymptote in nonlinear growth functions. Scientia Agricola 68: 109-114.

NETO, JV; OLMAR, F; MENEZES, G; SOUZA, PA. 2013. Produção e curva de crescimento de pepineiros para conserva em manejo convencional e com controle alternativo de pragas. Revista de Ciências Agroveterinárias, 12: 229-237.

PAINE, CET; MARTHEWS, TR; VOGT, DR; PURVES, D; REES, M; HECTOR, A; TURNBULL, LA. 2012. How to fit nonlinear plant growth models and calculate growth rates: An update for ecologists. Methods in Ecology and Evolution 3: 245-256.

PARAJULI, R; THOMA, G; MATLOCK, MD. 2019. Environmental sustainability of fruit and vegetable production supply chains in the face of climate change: A review. Science of The Total Environment 650: 2863-2879.

PRADO, TKL; SAVIAN, TV; MUNIZ, JA. 2013. Ajuste dos modelos Gompertz e Logístico aos dados de crescimento de frutos de coqueiro anão verde. Ciência Rural 43: 803-809.

RASHMI, B; NEGI, PS. 2020. Phenolic acids from vegetables: A review on processing stability and health benefits. Food Research International 109298.

RATKOWSKI, D. 1983. Nonlinear regression modeling: a unified practical approach. New York: M. Dekker. 276p.

SARI, BG; LÚCIO, AD; SANTANA, CS; OLIVOTO, T; DIEL, MI; KRYSCZUN, DK. 2019b. Nonlinear growth models: An alternative to ANOVA in tomato trials evaluation. European Journal of Agronomy 104: 21-36.

SARI, BG; LÚCIO, AD; SANTANA, CS; SAVIAN, TV. 2019a. Describing tomato plant production using growth models. Scientia Horticulturae 246: 146-154.

SARI, BG; OLIVOTO, T; DIEL, MI; KRYSCZUN, DK; LÚCIO, AD. 2018. Nonlinear modeling for analyzing data from multiple harvest crops. Agronomy Jounal 110: 1-12.

SEBER, GAF; WILD, CJ. 2003. Nonlinear regression. New Jersey: \&\#91;s.n.\&\#93;.

SHAPIRO, ASS; WILK, MB. 1965. Biometrika trust an analysis of variance test for normality (complete samples). Biometrika 52: 591-611.

SOUZA, EM; MUNIZ, JA; MARCHI, G; GUILHERME, LRG. 2010. Modelagem não linear da extração de zinco de um solo tratado com lodo de esgoto. Acta Scientiarum. Technology 32: 193-199.

SOUZA, G. 1998. Introdução aos modelos de regressão linear e não linear. Brasilia: Embrapa, 489p.

ZEVIANI, WM; SILVA, CA; CARNEIRO, WJO; MUNIZ, JA. 2012. Modelos não lineares para a liberação de potássio de estercos animais em latossolos. Ciência Rural 4: 1789-1796. 